\title{
EDUCAR COM COMPROMISSO SOCIAL: O PERFIL DE FORMAÇÃO DO PROFISSIONAL DE ENGENHARIA EM DEBATE
}

DOI: 10.37702/2175-957X.COBENGE.2021.3363

Leandro Bordin - Ibordin@uffs.edu.br Universidade Federal da Fronteira Sul Rua Lauro Muller $699 \mathrm{D}$ 89802-521 - Chapecó - SC

Resumo: O trabalho apresenta e discute os elementos considerados por professores engenheiros como essenciais na formação e atuação dos profissionais de engenharia. Considerando uma abordagem qualitativa, os dados e informações foram construídos por meio de entrevistas semiestruturadas com 29 (vinte e nove) professores de 5 (cinco) cursos de engenharia da Universidade Federal da Fronteira Sul e as análises e categorizações foram realizadas usando a metodologia de Análise de Conteúdo. A prevalência de concepções tradicionais acerca do processo educativo e da prática profissional, num lócus de pesquisa empírica que apresenta profícuas possibilidades de desenvolvimento de Tecnologias Sociais, reforça a falta de entendimento e comprometimento acerca do papel social da engenharia. Nesse sentido, fica evidenciado um considerável distanciamento entre os preceitos e contribuições do campo de estudos Ciência, Tecnologia e Sociedade (CTS), a formação e, consequentemente, as práticas profissionais no campo das engenharias.

Palavras-chave: Ciência, Tecnologia e Sociedade (CTS). Educação em Engenharia. Adequação sociotécnica. 


\section{EDUCAR COM COMPROMISSO SOCIAL: O PERFIL DE FORMAÇÃO DO PROFISSIONAL DE ENGENHARIA EM DEBATE}

\section{INTRODUÇÃO}

Num contexto hegemônico no qual ciência e tecnologia são, ainda, tratadas como neutras e deterministas, há de se considerar que o ensino de engenharia precisa ser repensado e atualizado com o propósito de articular discussões que extrapolem o puramente técnico da profissão. Apesar das muitas e expressivas produções no âmbito do campo de estudos CTS, as quais estão em estreito alinhamento com as ponderações que serão feitas ao longo deste artigo, é preciso admitir, infelizmente, pouca efetividade dessa abordagem nos processos educacionais no campo das engenharias. Por conta disso, seguimos perpetuando um paradoxo na profissão: ao mesmo tempo em que almejamos que nossos estudantes e profissionais desenvolvam características de criticidade, coletividade e solidariedade, continuamos tratando de forma dicotômica as questões técnicas e sociais que constituem a formação e a atuação da engenharia.

Nesse contexto, algumas indagações norteiam a construção deste trabalho. De que forma o desenvolvimento tecnológico e suas implicações em termos de desenvolvimento social é percebido e discutido nos cursos de engenharia? O processo educativo, para além da formação técnica/tecnológica, dá conta de formar cidadãos verdadeiramente comprometidos e responsáveis com os problemas - sociais, políticos, econômicos e ambientais - contemporâneos?

Ao investigar as concepções dos professores formadores acerca da sempre simbiótica relação entre desenvolvimento tecnológico e desenvolvimento social - desenvolvimento sociotécnico - e sua materialização durante o processo de formação e, posterior, atuação do estudante de engenharia o objetivo da discussão é ressaltar as potencialidades - e a urgente necessidade - de uma educação em engenharia mais crítica, integradora e interdisciplinar.

\section{A DIMENSÃO SOCIAL - E HUMANA - DAS SOLUÇÕES DE ENGENHARIA}

Galeano (2007) escreve sobre a escola do mundo ao avesso e por meio de um texto poético e irônico, por onde desfila uma enorme quantidade de fatos históricos e jornalísticos, reflete sobre a incapacidade do ser humano de harmonizar justiça e liberdade. Sobre o mundo ao avesso, onde o comportamento não segue uma lógica visto que as pessoas fazem justamente o contrário do que se espera delas, o trabalho do autor revela uma lista de barbaridades que o ser humano é capaz de ver e cometer. Na escola do mundo ao avesso, os estudantes frequentam cursos básicos de injustiça, de racismo e machismo, assistem aulas sobre medo e impunidade, todas elaboradas através da pedagogia da solidão. Ao longo de todo o texto, o autor apresenta um dossiê - verdadeiro e cruel - da triste e injusta realidade que parece se acentuar cada vez mais.

[...] hoje temos máquinas de aprendizagem que podem fazer coisas muito mais inteligentes que os humanos. Então, pela primeira vez na história, a inteligência não está só do lado dos humanos. Logo, qual é a última fronteira da humanidade? É a consciência, algo que não pode ser substituído por nenhuma máquina. $E$ a dimensão da consciência precisa 
estar presente no currículo, por isso, não podemos esquecer da história, da sociologia, da filosofia, tudo que nos dá essa outra dimensão (NÓVOA, 2017, p. 1, grifo meu)

Nessa direção, Postman e Weingartner (1971) há mais de quatro décadas escreveram sobre uma nova fórmula de ensino que se mantém bastante atual. Considerando os atuais moldes da educação em engenharia, então, é possível extrair inúmeras lições. De forma totalmente alinhada com as discussões aqui levantadas, os autores partem dos pressupostos de: (1) que a sobrevivência da sociedade está ameaçada por um número crescente de problemas inéditos e, até a data, insolúveis; e (2) que alguma coisa poderá ser feita para melhorar a situação.

A aposta, para uma possível mudança, é numa nova abordagem de educação. Os autores acreditam no aperfeiçoamento da condição humana através de uma educação mais reflexiva, crítica, libertadora, humanitária, contextualizada e comprometida com os problemas coletivos. Trabalhar com o argumento de que "a mudança - constante, acelerada, ubíqua - é a característica mais impressionante do mundo em que vivemos e que o nosso sistema educacional ainda não reconheceu isso" é admitir que a educação em engenharia, da forma como se apresenta, oferece poucas oportunidades para que os futuros engenheiros estejam sensíveis e conscientes da realidade - sociotécnica - que os cerca (POSTMAN; WEINGARTNER, 1971, p. 16).

Fraga, Novaes e Dagnino (2010, p. 232), Bazzo (2014) e Linsingen (2015) apostam que uma 'nova' educação em engenharia - verdadeiramente comprometida com o caráter sociotécnico da profissão - não passa pelo simples fato de acrescentar no currículo disciplinas da área de Humanidades. Para os autores, a raiz da questão centra-se em mudanças epistemológicas acerca, principalmente, da neutralidade e do determinismo da tecnociência. "Alavancar uma sociedade alternativa, baseada em outros valores, interesses e atores, exige do engenheiro uma reflexão profunda sobre a não neutralidade da tecnociência e a relação que esta tem com as forças que estruturam a sociedade".

Postman e Weingartner (1971, p. 111) apostam numa educação mais significativa, questionadora, calcada na resolução de problemas e com práticas interdisciplinares. Os autores defendem que é preciso deixar de lado a expressão "não fugir da matéria" e abrir espaço para discussões que expandam a consciência crítica do estudante. Ou seja, devese abrir espaço para diálogos autênticos e relevantes com trocas de experiências que efetivamente construam uma base sólida de conhecimentos numa perspectiva sociotécnica. Ao encontro disso, Nóvoa (2017, p. 1) ao falar sobre a necessidade de compreendermos a educação - pública - como compromisso social, nos inspira a pensar que fugir da matéria é, em boa medida, ter a consciência de que "não resolvemos nossos problemas se não resolvermos o problema dos outros".

Diante disso, é importante ter em pauta como os cenários econômicos, políticos, sociais e culturais contribuíram historicamente e ainda contribuem para o desenvolvimento da ciência e da tecnologia e direcionaram suas práticas em termos, inclusive, de educação. Igualmente importante é perceber e refletir como a educação tecnológica ainda é fortemente atrelada ao desenvolvimento econômico e aos processos de modernização, de maneira a atender, via de regra, as demandas impostas pelo modo de produção capitalista.

Nesse sentido, Dagnino, Brandão e Novaes (2004) apresentam o conceito de Adequação Sociotécnica (AST) como forma de operacionalização da Tecnologia Social (TS). A AST tem o objetivo de adequar a Tecnologia Convencional (TC), também chamada de Tecnologia Capitalista, - e, inclusive, conceber alternativas - de acordo com 
critérios suplementares aos técnico-econômicos convencionais a processos de produção e circulação de bens e serviços.

AST pode ser compreendida como um processo que busca promover uma adequação do conhecimento científico e tecnológico (esteja ele já incorporado em equipamentos, insumos e formas de organização da produção, ou ainda sob a forma intangível e mesmo tácita) não apenas aos requisitos e finalidades de caráter técnico-econômico, como até agora tem sido o usual, mas ao conjunto de aspectos de natureza socioeconômica e ambiental que constituem a relação CTS (DAGNINO; BRANDÃO; NOVAES, 2004, p. 52)

$\mathrm{Na}$ mesma direção, Thomas (2008, p. 259) destaca que "os processos de adequação sociotécnica permitem abrir a caixa preta do "sucesso" ou "fracasso" de uma tecnologia, explicar a adoção de uma tecnologia como um fenômeno sócio-historicamente situado e articular processos de co-construção de sistemas tecnológicos e usuários de tecnologias". Além de superar termos como "adequação ao entorno" e "contextualização" a AST, na visão do autor, é um "conceito chave para a superação de problemas teóricos tanto nas análises como no projeto e implementação de tecnologias e, ainda, de políticas públicas de ciência, tecnologia e inovação".

Essa perspectiva sociotécnica - fortemente aderida à TS - estimula o desenvolvimento de tecnologias no âmbito de uma lógica solidária e não a do capital. Para além de atribuir fundamental importância para os aspectos sociais e ambientais tradicionalmente tratados como secundários no desenvolvimento da $\mathrm{TC}-$, estimula a participação de atores, quase sempre, excluídos do processo de desenvolvimento tecnológico (DAGNINO; BRANDÃO; NOVAES, 2004).

\section{PROCEDIMENTOS METODOLÓGICOS}

A investigação em questão teve como lócus os 5 (cinco) cursos de engenharia ofertados pela Universidade Federal da Fronteira Sul (UFFS): Engenharia Ambiental e Sanitária (nos campi de Chapecó/SC, Erechim/RS e Cerro Largo/RS); Engenharia de Aquicultura (no campus Laranjeiras do Sul/PR); e Engenharia de Alimentos (no campus Laranjeiras do Sul/PR).

A escolha metodológica da UFFS como estudo de caso se deve, principalmente, ao seu perfil institucional, o qual apresenta, num contexto contra hegemônico, profícuas possibilidades para o desenvolvimento de Tecnologias Sociais e, nessa direção, para um percurso formativo verdadeiramente comprometido com as relações sociotécnicas das soluções de engenharia. Neste sentido, convém destacar três aspectos: a vinculação da UFFS com movimentos sociais desde sua idealização, criação e processo de consolidação; a marca institucional popular amplamente sublinhada nos documentos e práticas institucionais; e por fim, o compromisso com o desenvolvimento regional integrado, sustentável e solidário.

Para investigar o(s) direcionamento(s) dado(s) pelos professores na formação e na, consequente, atuação do profissional de engenharia foi definido como critério de inclusão que os docentes entrevistados deveriam ministrar disciplinas no domínio específico dos cursos em questão. No âmbito da UFFS, que organiza o currículo de seus cursos em torno de três domínios - comum, conexo e específico -, o domínio específico é composto basicamente pelos componentes curriculares e atividades que envolvem exclusivamente a área de foco do curso de graduação. Entendida como a formação que permitirá ao 
estudante o exercício profissional, este domínio nos cursos de engenharia é composto em sua totalidade - ou quase totalidade - por professores com formação em engenharia.

O contato com as coordenações de curso permitiu identificar 42 (quarenta e dois) professores que atenderam os critérios de inclusão da pesquisa. Após os contatos individuais terem sido realizados, 29 (vinte e nove) convites foram aceitos, o que corresponde a uma amostra de $69 \%$ (sessenta e nove por cento) do total inicialmente projetado.

A análise das entrevistas foi realizada por meio da metodologia de Análise de Conteúdo. O percurso metodológico começou pela definição de categorias primeiras de análise, nesse caso "O perfil do profissional de engenharia construído pelos professores formadores". Tal definição orientou a formulação das perguntas que, ao serem elaboradas e discutidas com cada entrevistado, pudessem apresentar elementos para a compreensão da temática. A Análise de Conteúdo conduz a análise por um percurso organizado do qual emergem novas compreensões e entendimentos sobre o fenômeno estudado. Constitui-se de cinco momentos metodológicos: (1) preparação, (2) unitarização, (3) (sub)categorização, (4) descrição e (5) análise/interpretação (BARDIN, 1977; MORAES, 1999).

A etapa de preparação foi composta pela organização e codificação do material transcrito. Também, fez parte dessa etapa uma primeira leitura compreensiva, nos termos de Engers (2000), com a qual se buscou traçar as primeiras relações entre o conteúdo dos textos e a construção teórica acerca do tema estudado. O trabalho continuou pela identificação em cada entrevista dos elementos de fala relacionados com a categoria primeira analisada. O trabalho, nesse ponto, foi, então, de varredura do texto por meio de uma ou mais leituras a fim de encontrar todos os elementos relevantes relacionados com a categoria primeira. Nesse movimento circular e cíclico que constitui a unitarização foi possível identificar convergências e divergências por meio de unidades de análise e, então, destacar subcategorias emergentes do conjunto de entrevistas. Tais subcategorias constituem os principais elementos de problematização e discussão sobre a temática pesquisada.

\section{O QUE DIZEM - E FAZEM - OS PROFESSORES FORMADORES}

As questões (1) Em sua concepção, o que é um bom profissional de engenharia? e (2) $O(A)$ senhor(a) considera que a organização curricular do curso de engenharia no qual atua na UFFS da conta de formar bons profissionais de engenharia e quais indicadores utiliza para dar essa resposta?, foram os elementos disparadores da entrevista.

Para organizar as tantas informações e relações provenientes das falas dos professores - identificados pela letra $\mathrm{P}$-, o quadro 1 apresenta um modelo do percurso de ir e vir do movimento de desconstrução do texto inicialmente analisado - unitarização e, posteriormente, de construção dos novos significados - (sub)categorização - em busca de responder aos objetivos da pesquisa - análise/interpretação. 
Quadro 1: Modelo do processo de unitarização e (sub)categorização

\begin{tabular}{|c|c|}
\hline O perfil do profissional de engenharia construído pelos professores formadores \\
\hline $\begin{array}{c}\text { Unidades de análise } \\
\text { Termos/Expressões mais representativos(as) }\end{array}$ & $\begin{array}{c}\text { Subcategorias de } \\
\text { análise }\end{array}$ \\
\hline $\begin{array}{c}\text { (Excertos das falas dos professores com destaque para os termos mais } \\
\text { representativos) }\end{array}$ & $\begin{array}{c}\text { Construção/Definição } \\
\text { da categoria emergente }\end{array}$ \\
\hline
\end{tabular}

Fonte: Do autor

Como forma de sintetizar os resultados das construções feitas por meio do quadro 1 , a figura 1 apresenta as subcategorias de análise para a categoria: o perfil do profissional de Engenharia construído pelos professores formadores.

Figura 1: Síntese das subcategorias de análise: O perfil do profissional de Engenharia construído pelos professores formadores

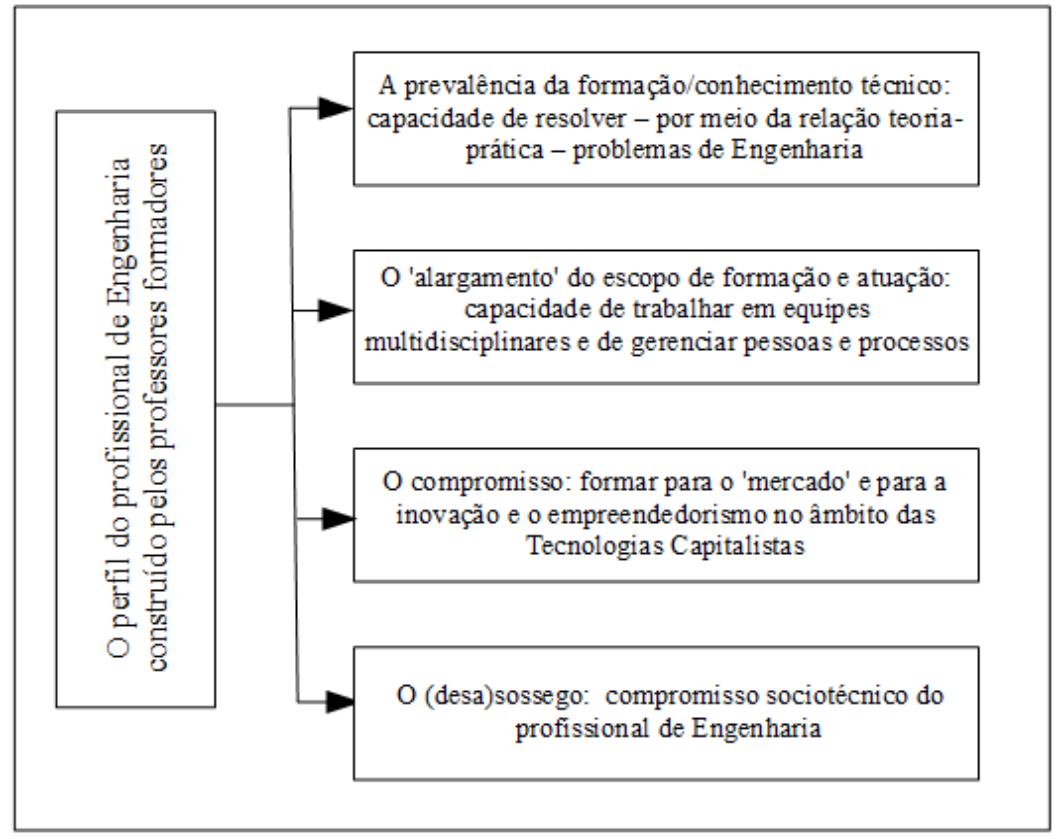

Fonte: Do autor

A partir deste ponto cada uma das quatro subcategorias serão discutidas por meio de um texto síntese - descrição - na tentativa de estabelecer relações análise/comunicação - com os elementos construídos ao longo deste trabalho.

\subsection{A prevalência da formação/conhecimento técnico: capacidade de resolver - por meio da relação teoria-prática - problemas de engenharia}

Quando o assunto é a prioridade na formação e atuação do profissional de engenharia os aspectos técnicos são destaque. $O$ arcabouço teórico construído ao longo deste trabalho já sinalizava a dicotomia, historicamente reproduzida, entre desenvolvimento tecnológico e desenvolvimento social no âmbito da formação/atuação. $O$ 
primeiro elemento de fala dos professores entrevistados quando o assunto é perfil do profissional de engenharia é, via de regra, formação/conhecimento técnico. Como veremos adiante, poucos formadores articulam suas falas em torno da atuação sociotécnica da engenharia.

Assim, não é surpresa, e o leitor poderia dizer que é até esperado, encontrarmos entendimentos como os seguintes:

Eu sou bastante ferrenho, defensor de uma formação técnica bastante forte. Essa é principal característica, essa é a característica básica da engenharia (P24).

Se não é surpresa, e até esperado, encontrar a maioria das concepções acerca das atribuições profissionais vinculadas a resolução de problemas de ordem técnica por que, então, busquei investigar tal aspecto nessa pesquisa? A resposta é simples: no contexto da UFFS, que se projeta como desenvolvedora de Tecnologias Sociais, investigar as concepções dos professores acerca da abrangência da formação e atuação profissional, nesse âmbito, é primordial. Afinal, seus entendimentos sobre a profissão estarão, certamente, refletidos em suas práticas docentes.

Com estreita aderência à perspectiva sociotécnica que tenho construído no decorrer deste trabalho, o perfil do egresso preconizado pelas Diretrizes Curriculares Nacionais para a educação em engenharia (DCNs) - profissional capaz de projetar soluções numa perspectiva multidisciplinar e transdisciplinar, considerando os aspectos globais, políticos, econômicos, sociais, ambientais, culturais e ainda atuando com isenção de qualquer tipo de discriminação e comprometido com a responsabilidade social e o desenvolvimento sustentável (BRASIL, 2019) - não encontra materialidade. A resolução de problemas de engenharia que leve em conta seus aspectos políticos, econômicos, sociais, ambientais e culturais encontra sérias dificuldades de concretização nos atuais moldes da formação profissional. As concepções que fizeram emergir a subcategoria ora apresentada são bastante reveladoras de tal problemática.

Tais considerações começam a nos indicar que os professores formadores vinculados ao domínio específico dos cursos de engenharia apresentam dificuldades em materializar o projeto de universidade desenhado pela UFFS. Mesmo mudando substancialmente o cenário, as concepções docentes sobre o perfil do profissional de engenharia tendem para a manutenção da dificuldade de efetivar uma formação/atuação profissional para a adequação sociotécnica.

Para garantir que o profissional de engenharia consiga encontrar soluções que resolvam os problemas técnicos do cotidiano, muitos dos professores que destacam o conhecimento técnico como prioritário estão preocupados com a relação teoria-prática. Assim, falam:

Acredito que uma boa formação para um aluno não se dá apenas na parte de conhecimentos técnicos. Precisamos instigar esse aluno a ter uma postura no mercado de trabalho... Eu vejo que a educação, a sala de aula, se fecha naquela coisa do teórico - que claro, é importante - mas que a gente possa ter essa... como é que eu posso dizer? Relação teoria-prática (P1).

Convém destacar que a relação entre o 'saber' e o 'fazer' é de grande importância. No entanto, quando reforça a dicotomia entre o caráter técnico e social da engenharia, como acontece nesses casos, fica suscetível à duras críticas. 


\subsection{O 'alargamento' do escopo de formação e atuação: capacidade de trabalhar em equipes multidisciplinares e de gerir pessoas e processos}

Para ampliar a ênfase na formação/conhecimento técnico do profissional de engenharia, os professores mencionam a capacidade de trabalho em equipe e de gerenciar pessoas e processos. As falas, nesse sentido, estão sempre atreladas ao que falta na formação/atuação. É como se no campo da técnica tudo andasse bem e que para alargar o escopo de trabalho profissional seria preciso, unicamente, desenvolver a habilidade de trabalho em equipes multidisciplinares e as competências de planejamento e gestão.

Um bom profissional de engenharia tem que ter uma base técnica, mas ele tem que ter uma capacidade de inter-relação com o grupo [de trabalho] (P26).

... o engenheiro na vida profissional, ele vai fazer gestão, ele vai trabalhar em equipe, ele vai ter que tomar decisões rápidas (P11).

Convém esclarecer que ao destacar a capacidade de trabalhar em equipes multidisciplinares, via de regra, os professores continuam valorizando a resolução de problemas estritamente relacionados ao escopo técnico da profissão. A equipe, a que essas ponderações se referem, é composta apenas por profissionais de engenharia reunidos para colaborativamente resolverem as parcelas do empreendimento referentes a suas especialidades.

No âmbito da adequação sociotécnica essa condição é necessária, mas não suficiente. Se a resolução de problemas se der, apenas, pelo viés de profissionais engenheiros preocupados prioritariamente com o aspecto técnico, a dicotomia com o desenvolvimento social continuará presente. Defendo, neste ponto, que a formação/atuação profissional deve congregar diferentes áreas do conhecimento e, portanto, contemplar as tantas outras variáveis envolvidas nas soluções tecnológicas.

A falta de clareza sobre o que seja trabalhar em equipe está presente inclusive nas DCNs, tanto na versão de 2002 quanto na recém-publicada no ano de 2019 (BRASIL, 2002; 2019). Nos referidos documentos é destacada a capacidade de atuar em equipes multidisciplinares sem qualquer esclarecimento sobre o que de fato isso significa. A confusão segue, então, se refletindo nos projetos de curso e nas concepções e atividades docentes.

Para além da capacidade de trabalho em equipe, outra necessidade revelada nas entrevistas diz respeito aos aspectos da gestão de pessoas e processos. Isso porque é quase consenso de que o egresso é contratado, muitas vezes, para desempenhar as referidas funções.

... então, é um profissional bem versátil; ele tem que ter muita capacidade de trabalhar em diversas áreas... Dou exemplo de outros colegas meus, de onde trabalham, o que fazem; porque o pessoal vai diversificando, não é? Hoje tenho colegas que trabalham com logística; o pessoal trabalha em diversas áreas; a própria questão de [setor de] vendas (P18, grifo meu).

A reflexão que eu faço as vezes é que a engenharia, especialmente no Brasil, andou para trás e bastante. Então a gente não consegue cumprir prazo, não consegue fazer projeto que seja redondo, que você possa cumprir prazo, que 
possa cumprir verba... você faz muita coisa errada por falta de planejamento (P17, grifo meu).

Convém destacar, novamente, que neste ensaio de 'alargamento' do escopo de formação e atuação profissional, não são mencionados elementos que possibilitem perceber a superação da dicotomia entre os aspectos técnicos e as questões sociais da/na engenharia.

\subsection{O compromisso: formar para o 'mercado' e para a inovação e o empreendedorismo no âmbito das Tecnologias Capitalistas}

$\mathrm{Na}$ contramão do compromisso assumido pela UFFS com o desenvolvimento regional integrado, sustentável e solidário - e, portanto, fortemente ancorado no desenvolvimento de Tecnologias Sociais -, uma preocupação recorrente dos professores é a profissionalização para o 'mercado' de trabalho. Esse ente, o mercado, parece o responsável pela falta de prioridade com a formação humana, com a inclusão social e com a atenuação das desigualdades.

Se tu perguntares: "o curso que vocês estão ofertando é completo?", eu vou te dizer: não falta nada. Nada. Até a disciplina de [Introdução à] Informática que a gente tinha como rol de domínio comum, mudou para Computação [Básica], porque a gente entende que eles [os estudantes] precisam para cálculo numérico. Então ele não perde para nenhum outro curso e inclusive eu acredito que ele tenha até aspectos que fazem com que ele seja até melhor do que outros cursos mais clássicos. Principalmente porque ele [o curso] forma pelas ações do mercado de trabalho (P23, grifo meu).

O preocupante, nesse contexto, é a falta de criticidade sobre quais interesses movem, de fato, o mercado. O discurso naturalizado e hegemônico do capitalismo se reveste de um conformismo assustador. O compromisso reside na formação de profissionais técnicos que sejam absorvidos pelo mercado e não na educação de seres humanos capazes de se contrapor ao modelo de desenvolvimento tecnológico cujos produtos e processos obedecem a lógica de um sistema, em grande medida, excludente.

Convém esclarecer, neste ponto, que (re)produzir Tecnologias Capitalistas é alimentar um sistema no qual as desigualdades são entendidas como mero efeito colateral do desenvolvimento tecnológico. A presença de tal aspecto na centralidade do processo formativo dos cursos de engenharia da UFFS revela ainda mais dificuldades em efetivarmos uma formação/atuação para a adequação sociotécnica.

$\mathrm{Na}$ profissionalização para o 'mercado', outras duas palavras de ordem são manifestadas: inovação e empreendedorismo.

Além de conhecimento técnico, criatividade, capacidade de inovação para mim é essencial... (P2, grifo meu).

E a gente tem falado muito no curso, é um trabalho que a gente tem feito muito com outros professores também, é falar de empreendedorismo. Para os alunos pensarem em ser engenheiros e empreendedores, que é uma das formas que eles conseguem daí viver bem tranquilos e ganhar dinheiro com a engenharia (P18, grifo meu). 
Convém destacar que inovação e empreendedorismo são dois novos importantes elementos trazidos pelas DCNs publicadas no ano de 2019 (BRASIL, 2019). A leitura dos documentos e a participação nas discussões promovidas pela Associação Brasileira de Educação em Engenharia (ABENGE), permitem constatar que 'inovação' e 'empreendedorismo' aparecem, via de regra, vinculados ao desenvolvimento de Tecnologias Capitalistas. O ente 'mercado', travestido de gestores e educadores dos cursos de engenharia, é o demandante e o direcionador dessa 'nova' abordagem presente nas discussões e nos direcionamentos de formação e a atuação profissional.

Falar em inovação e em empreendedorismo - especialmente no âmbito da UFFS e da adequação sociotécnica -, sem fazer vinculação com desenvolvimento social contribui para acentuar as incoerências entre a universidade pública e popular, a engenharia e o desenvolvimento de Tecnologias Sociais. Nesse sentido, defendo que por meio do estímulo e do desenvolvimento de ações de empreendedorismo social e de inovações de impacto social será possível caminhar na direção da adequação sociotécnica.

\subsection{0 (desa)sossego: compromisso sociotécnico do profissional de engenharia}

Em menor número, mas com grande importância, foi possível identificar nas unidades de análise concepções acerca da atuação do profissional de engenharia em total alinhamento com a perspectiva sociotécnica de educação aqui defendida. Sobressaem falas impregnadas de inquietação - de desassossegos. Alguns professores não sabem muito bem como explicar a necessidade de um profissional diferente dos que costumeiramente são formados nos cursos de engenharia e tampouco têm clareza de como materializar, na organização curricular, elementos formativos para além dos puramente técnicos. No entanto, entendem que a formação/atuação do profissional de engenharia é mais ampla que apenas desenvolver soluções técnicas para problemas de engenharia.

O que eu sinto que falta hoje em dia, e tu vê, eu passei pela indústria, é que às vezes as pessoas não estão nem aí para o ser humano, as pessoas querem produção, querem produzir cada vez mais, não importa a quem custar. Parece que esse lado humano está um pouco de lado (P7, grifo meu).

Ao mesmo tempo, percebe-se concepções claras e objetivas acerca do compromisso sociotécnico do profissional de engenharia. Nesses casos, as falas são precisas, contundentes e carregadas de elementos e argumentos que corroboram a defesa de uma educação mais crítica, integradora e comprometida com o bem viver coletivo.

Então para mim é pressuposto que ele (o profissional de engenharia) tenha uma visão crítica da sociedade, sobre as desigualdades. Quer dizer... enfim, a engenharia, supostamente, é para ajudar a desenvolver e melhorar a vida das pessoas, mas se não faz isso ou se o mundo não faz isso, por que é que não faz? Então é entender isso e situar o trabalho dentro disso. Por isso a questão social, política, cidadã ou mesmo a inserção, a aproximação com os atores sociais, não é? Não apenas com os formais, com os que são... vamos dizer, comumente considerados, mas também com os movimentos sociais, com os grupos e setores mais marginalizados da sociedade, eles também são importantes. Então uma formação de engenharia deveria ser uma formação sólida tecnologicamente, mas também do método de trabalho, do jeito de 
trabalho, da preocupação e da sensibilidade social, de perceber que mesmo você estando em uma empresa de engenharia ou uma empresa grande você tem uma função social, uma responsabilidade social, uma questão de solidariedade com as outras pessoas e com o país e o mundo, enfim. Eu acho que essa ideia deveria ser parte de uma formação humana mais integral do engenheiro, não é? O engenheiro não é só uma máquina de produção de projetos ou de técnicas. Ele é um ser humano em relação no mundo. Então essa compreensão deveria ser parte do processo de formação (P20).

Concepções acerca da formação/atuação do profissional de engenharia como as supracitadas configuram importantes elementos acerca da materialidade de um profissional capaz de atuar na superação da dicotomia entre desenvolvimento tecnológico e desenvolvimento social.

\section{CONSIDERAÇÕES FINAIS}

Ao encaminhar o trabalho para suas considerações finais é preciso registrar que as concepções neutras e deterministas a respeito do desenvolvimento tecnológico ainda são marcantes no processo formativo dos cursos de engenharia, objetos dessa análise. $O$ desenvolvimento de soluções tecnológicas considerando sua linearidade com desenvolvimento econômico repercutem na idealização e na formação de um profissional preocupado prioritariamente com questões técnicas num contexto capitalista.

Convém destacar, portanto, que a sólida formação técnica e tecnológica que os cursos de engenharia se esforçam para promover está, neste trabalho, sendo questionada, uma vez que compreendo que tal solidez só será plena na medida em que as questões do desenvolvimento social estejam, de fato, presentes no cenário educativo. Ao entender e destacar o potencial da Engenharia como propulsora de desenvolvimento, reitero a necessidade de uma formação mais consistente e integradora, na qual as soluções tecnológicas sejam direcionadas por uma abordagem sociotécnica.

Caso contrário, o compromisso da engenharia com o desenvolvimento de tecnologias em atendimento as demandas da sociedade continuará revestido de um caráter seletivo e parcelar. Num olhar crítico sobre esse cenário é possível entender porque uma formação na qual os aspectos políticos, sociais, econômicos e ambientais sejam parte integrante das soluções tecnológicas se mantém, historicamente, no status de utopia.

Para avançarmos, então, na direção de uma educação em engenharia verdadeiramente comprometida com a adequação sociotécnica é preciso (re)discutir as articulações dos currículos e das atividades docentes de ensino, pesquisa e extensão frente a essa nova perspectiva. Nesse sentido, a implantação de políticas e programas de formação de professores para a adequação sociotécnica se torna uma premente necessidade. Afinal, são os professores formadores - quase sempre com formação em engenharia - os responsáveis pela elaboração dos projetos de curso e seus direcionamentos e pela formação do estudante e futuro profissional.

Ao reforçar a ideia de equilíbrio e equalização dos aspectos técnicos e sociais o que pretendo é tornar presente que o desenvolvimento de caráter sociotécnico é aquele que opera para além das forças do mercado capitalista e contribui, em diferentes contextos, para a promoção de soluções mais inclusivas, participativas e democráticas. 


\section{REFERÊNCIAS}

BARDIN, Laurence. Análise de Conteúdo. Lisboa: Edições 70, 1977.

BAZZO, Walter Antonio. Ciência, Tecnologia e Sociedade e o contexto da educação tecnológica. 4. ed. rev. Florianópolis: Ed. da UFSC, 2014.

BRASIL. Resolução CNE/CES 11/2002. Diário Oficial da União, Brasília, 9 de abril de 2002. Seção 1, p. 32-35.

BRASIL. Resolução CNE/CES 2/2019: Diretrizes Curriculares Nacionais do Curso de Graduação em Engenharia. Brasília, 2019.

DAGNINO, Renato Peixoto.; BRANDÃO, Flávio Cruvinel.; NOVAES, Henrique Tahan. Sobre o marco analítico conceitual da tecnologia social. In: LASSANCE Jr. et al. (Org). Tecnologia Social: uma estratégia para o desenvolvimento. Rio de Janeiro, Fundação Banco do Brasil, 2004. p. 15-64.

ENGERS, M. E. A. A pesquisa no contexto da universidade: um novo olhar para a realidade da PUCRS. Educação Brasileira, Brasília, v. 22, n. 44, p. 131-154, jan./jun. 2000.

FRAGA, Lais Silveira. NOVAES, Henrique T. DAGNINO, Renato Peixoto. Educação em Ciência, tecnologia e sociedade para as engenharias: obstáculos e propostas. In: DAGNINO, Renato (Org.). Estudos sociais da ciência e tecnologia e política de ciência e tecnologia: abordagens alternativas para uma nova América Latina. Campina Grande. Eduepb, 2010. p 213-234.

GALEANO, Eduardo. De pernas pro ar: a escola do mundo ao avesso. 9. ed. - Porto Alegre: L\&PM, 2007.

LINSINGEN, Irlan. Perspectivas curriculares CTS para o ensino de engenharia: uma proposta de formação universitária. Linhas Críticas (UnB), v. 21, p. 297-317, 2015.

MORAES, Roque. Análise de conteúdo. Revista Educação, Porto Alegre, v. 22, n. 37, p. 7-32, 1999.

NÓVOA, Antonio. Entrevista. (2017). Disponível em:

<http://http://www.cartaeducacao.com.br/reportagens/se-fosse-brasileiro-estariaindignado-com-a-situacao-da-educacao/>. Acesso em: 30 ago. 2019.

POSTMAN, Neil; WEINGARTNER, Charles. Contestação: nova fórmula de ensino. Rio e Janeiro: Editora Expressão e Cultura, 1971.

THOMAS, Hernan. Estructuras cerradas versus procesos dinámicos: trayectorias y estilos de innovación y cambio tecnológico. In: THOMAS, Hernan; BUCH, Alfonso (Org). Actos, actores y artefactos: sociologia de la tecnologia. Bernal: Universidad Nacional de Quilmes, 2008, p. 217-262. 


\title{
EDUCATE WITH SOCIAL COMMITMENT: THE PROFILE OF TRAINING OF THE ENGINEERING PROFESSIONAL IN DEBATE
}

\begin{abstract}
This document presents This work presents and discusses the elements considered by engineering teachers as essential in the educational process and in the professional practice of Engineering. Taking into consideration a qualitative approach, the data were constructed through semi-structured interviews with 29 professors from 5 engineering courses at Universidade Federal da Fronteira Sul and the analyses and subcategorizations were conducted via use of the Analysis of Content methodology. The prevalence of traditional conceptions about the educational process and professional practice in a locus of empirical research that presents meaningful possibilities for the development of Social Technologies, reinforces the lack of understanding and commitment around the social role of Engineering.In this sense, there is a considerable gap between the precepts and contributions of the field of studies Science, Technology and Society (STS), training and, consequently, professional practices in the field of engineering.
\end{abstract}

Keywords: Science, Technology and Society (STS); Education in engineering; Sociotechnical appropriateness. 